\title{
Complete genome sequence of Deltapapillomavirus 4 (bovine papillomavirus 2) from a bovine papillomavirus lesion in Amazon Region, Brazil
}

\author{
Cíntia Daudt' ${ }^{1}$, Flavio RC da Silva ${ }^{1,2}$, Samuel P Cibulski ${ }^{1}$, Matheus N Weber', \\ Fabiana Q Mayer ${ }^{3}$, Ana Paula M Varela ${ }^{4}$, Paulo M Roehe ${ }^{4}$, Cláudio W Canal'1/+ \\ ${ }^{1}$ Universidade Federal do Rio Grande do Sul, Faculdade de Veterinária, Laboratório de Virologia, Porto Alegre, RS, Brasil \\ ${ }^{2}$ Universidade Federal do Acre, Centro de Ciências Biológicas e da Natureza, Rio Branco, AC, Brasil \\ ${ }^{3}$ Fundação Estadual de Pesquisa Agropecuária, Instituto de Pesquisas Veterinárias Desidério Finamor, \\ Laboratório de Biologia Molecular, Eldorado do Sul, RS, Brasil ${ }^{4}$ Universidade Federal do Rio Grande do Sul, \\ Departamento de Microbiologia, Imunologia e Parasitologia, Laboratório de Virologia, Porto Alegre, RS, Brasil
}

The complete genome sequence of bovine papillomavirus 2 (BPV2) from Brazilian Amazon Region was determined using multiple-primed rolling circle amplification followed by Illumina sequencing. The genome is 7,947 bp long, with 45.9\% GC content. It encodes seven early (E1, E2, E4, E5, E6, E7, and E8) and two late (L1 and L2) genes. The complete genome of a BPV2 can help in future studies since this BPV type is highly reported worldwide although the lack of complete genome sequences available.

Key words: papillomavirus - bovine - BPV2 - complete genome

Papillomaviruses (PVs) are small, oncogenic, highly epitheliotropic viruses with marked tropism for squamous epithelia (Bravo \& Felez-Sanchez 2015). The genome of PVs is a circular molecule of double stranded DNA of about $8 \mathrm{~kb}$, which bears one of the slowest evolutionary rates among viruses (Rector et al. 2007).

Fifteen bovine papillomavirus (BPV) types have been recognised to date (BPV1-BPV15) and are classified into four genera and five species. BPV infections have been reported worldwide; among these, BPV2 has been reported as one of the most prevalent types (Hatama et al. 2011, Roperto et al. 2013, Araldi et al. 2014). The BPV2 is assigned to the Deltapapillomavirus genus species 4. Apart from causing infections in the original host (cattle), this virus type has been recovered from lesions in other species, such as the equines and in buffaloes (Corteggio et al. 2013, Kumar et al. 2015).

There are few studies on the genetic diversity and distribution of BPV in Brazil. Despite this paucity of data, it is known that the BPV2 is the most detected virus in Brazilian cattle (Batista et al. 2013, Araldi et al. 2014, da Silva et al. 2015). In order to expand the knowledge on the genetic diversity of the BPV2, the complete genome sequencing of an autochthonous BPV2 from the Brazilian Amazon Region is described.

A rolling circle amplification (RCA) was applied to $100 \mathrm{ng}$ of total DNA isolated from a papilloma lesion as

doi: $10.1590 / 0074-02760160047$

+Corresponding author: claudio.canal@ufrgs.br

Received 10 February 2016

Accepted 7 March 2016 previously described (Dezen et al. 2010, Rijsewijk et al. 2011). Neoplastic tissue was comprised by exophytic papillomatous, epithelium proliferation, and well-differentiated cells, marked acanthosis, koilocytes, increased amounts of granules in the granular layer, and keratohyalin granules. Libraries were prepared with Nextera DNA sample preparation kit (Illumina) using the RCA products and sequenced in an Illumina MiSeq System with MiSeq reagent kit v2 300 cycle. Reads were assembled into contigs using SPAdes 3.6 and compared to sequences in the GenBank nucleotide and protein databases using BLASTn/BLASTx. The Geneious software was used for open reading frame (ORF) predictions and genome annotations.

A total of 27,764 reads were produced, of which 8,116 were related to BPV2 (average reads length $111 \mathrm{nt}$ ). One full-length circular contig related to BPV2 was identified and annotated (mean coverage 92). The circular genome was named BPV2 BRA/09RO12. It spans 7,947 bp, with a $45.9 \%$ GC content (Figure). The genome potentially encodes seven early $(E 1, E 2, E 4, E 5, E 6, E 7$, and $E 8)$ and two late ORFs ( $L 1$ and $L 2)$. A 934 bp noncoding region (NCR) is located between the $L 1$ and E6 ORFs (Figure).

The gene $E 1$ encodes the largest viral protein (with helicase function), which contains 606 amino acids; the adenosine 5'-triphosphate (ATP)-binding site (GPPNTGKS) of the ATP-dependent helicase is present in the carboxy-terminal part of E1 (Titolo et al. 1999). The putative E6 protein exhibits two conserved zinc-binding domains of $\mathrm{CX}_{2} \mathrm{CX}_{29} \mathrm{CX}_{2} \mathrm{C}$ (Lehoux et al. 2009). The E5 protein shows a leucine-rich profile, while $\mathrm{E} 7$ exhibits a proline-rich profile. The NCR contains nine consensus palindromic E2-binding sites ( $\left.\mathrm{ACCN}_{6} \mathrm{GGT}\right)$, three putative TATA boxes (TATAAA) of E6 promoter, and the polyadenylation site (AATAAA) for $L 1$ and $L 2$ transcripts (Zheng \& Baker 2006, de Villiers \& Gunst 2009). 


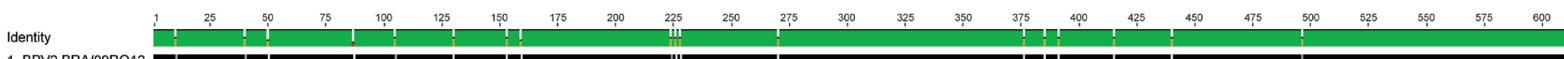

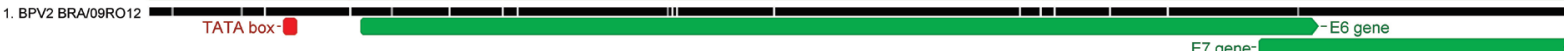

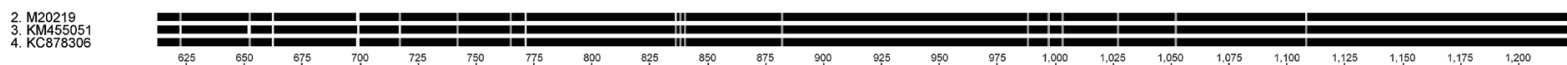

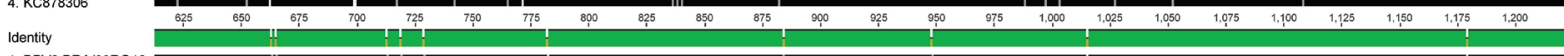
1. BPV2 BRA09R012

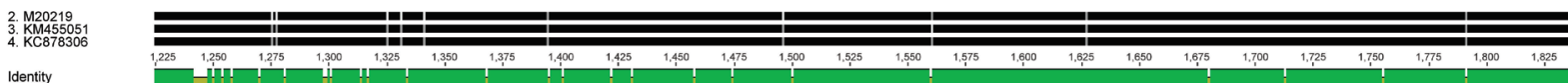

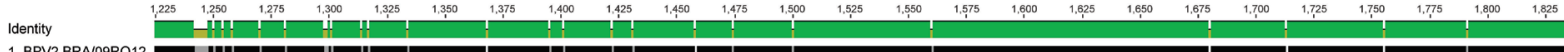
1. BPV2 BRA09R012

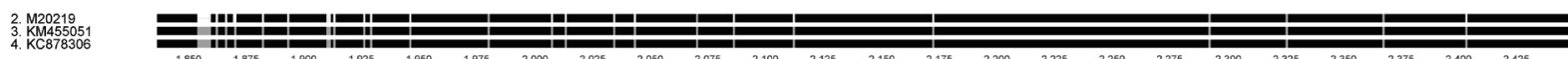

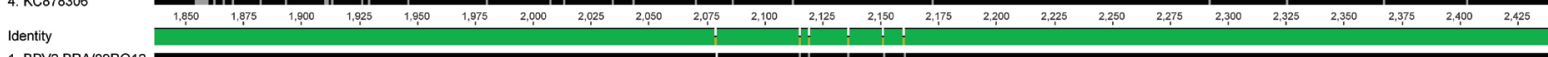
1. BPV2 BRA 098RO12 E1 gene

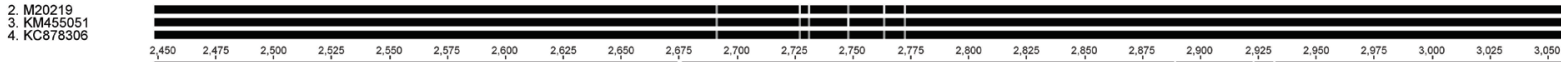

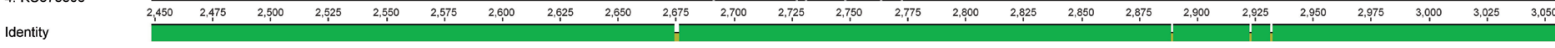

1. BPV2 BRA 09RO12 E2 gene-

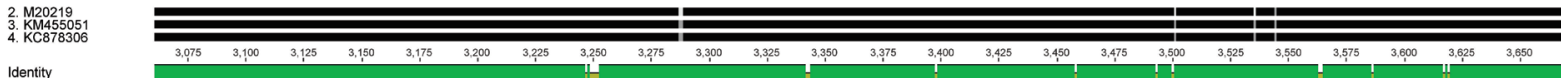

1. BPV2 BRA109RO12 E2 gene E4 gene- _ _

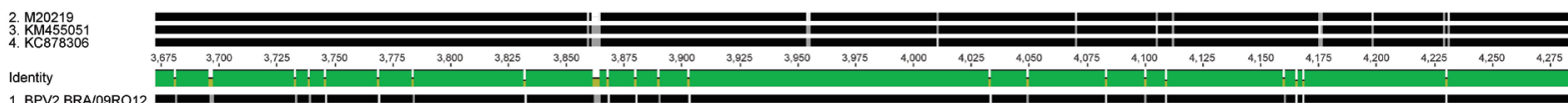
1. BPV2 BRA09RO12 -E2 gene

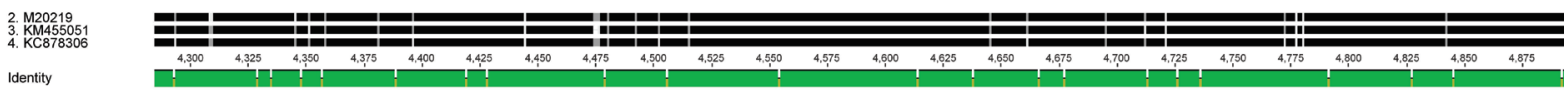

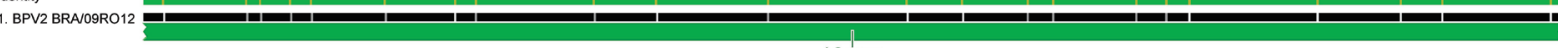
L2 gene

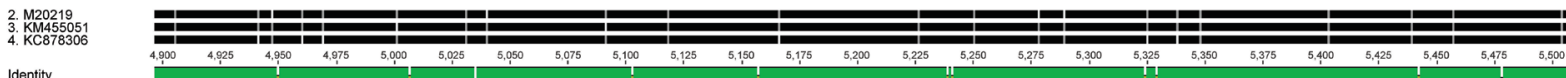

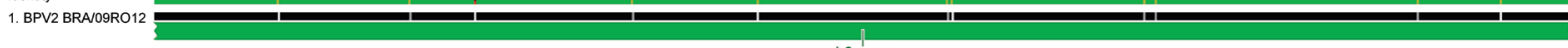
L2 gene

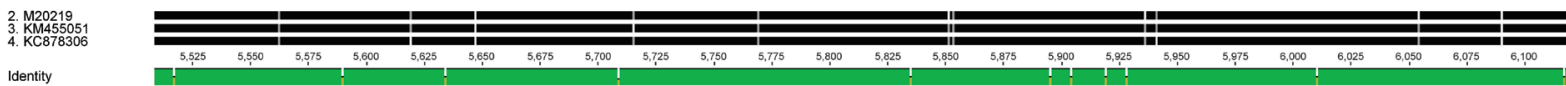

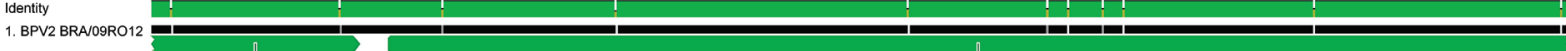
L2 gene

L1 gene

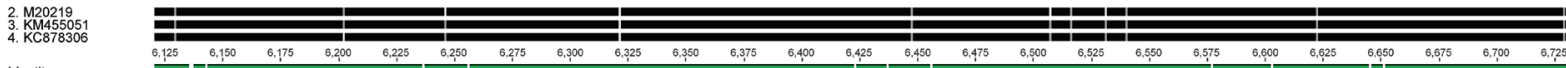

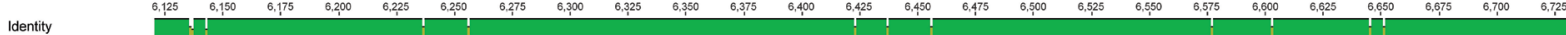
1. BPV2 BRA109R012

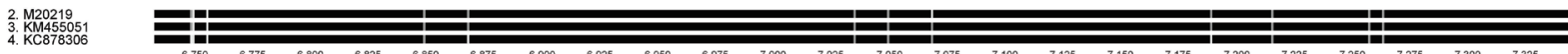

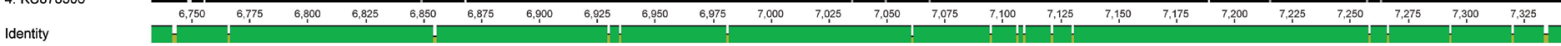
1. BPV2 BRA09RO12

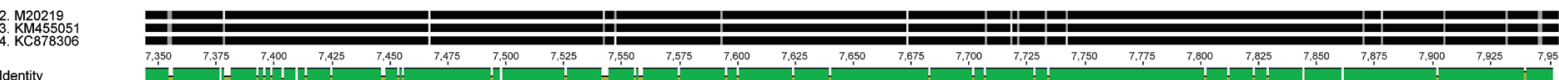

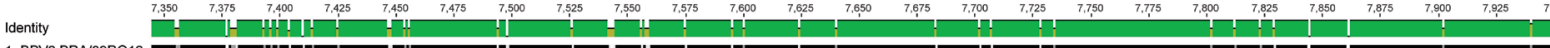
BPV2 BRA09RO12

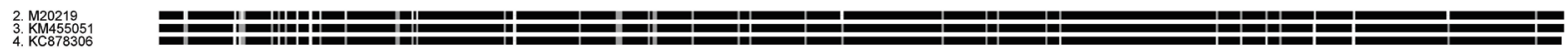

Nucleotide alignment of bovine papillomavirus 2 (BPV2) BRA/09RO12 with the complete genomes of BPV2 available in GenBank. Putative coding regions of BPV2 BRA/09RO12 for early $(E 1, E 2, E 4, E 5, E 6, E 7$, and E8) and late proteins (L1 and L2) are marked by arrows. 
The sequence reported here (BRA/09RO12) shares a high degree of nucleotide identity among BPV2 genomes available at GenBank $(97.7 \%$ with a North American BPV2 reference genome M20219 and $~ 98.5 \%$ with recently sequenced Chinese strains KC878306 and KM455051) (Figure). As expected, most differences in the nucleotide sequences were concentrated in the NCR and in the $E 8$ gene (Garcia-Vallve et al. 2006). Double stranded viruses show the slowest evolutionary rates among viruses (Sanjuan et al. 2010). As example, two BPV1 sequences reported in Sweden and in United States of America more than 30 years apart displayed 99.89\% nucleotide identity, not different from the standing genetic variation of this virus (Ahola et al. 1983).

The complete genome of BPV2 BRA/09RO12 is the first complete BPV2 recovered from Brazilian cattle reared in the Amazon Region. It reveals a high degree of identity ( $>97 \%$ ) with previously published BPV2 reported elsewhere, thus confirming the worldwide prevalence of such virus type. This sequence is expected to assist future studies on genetic comparisons and characterisation of PV genomes.

Nucleotide sequence accession - The complete genome sequence of BPV2 strain BRA/09RO12 is available in GenBank under the accession KU674833.

\section{REFERENCES}

Ahola H, Stenlund A, Moreno-Lopez J, Pettersson U 1983. Sequences of bovine papillomavirus type 1 DNA-functional and evolutionary implications. Nucleic Acids Res 11: 2639-2650.

Araldi RP, Giovanni DN, Melo TC, Diniz N, Mazzuchelli-de-Souza J, Sant'Ana TA, Carvalho RF, Becak W, Stocco RC 2014. Bovine papillomavirus isolation by ultracentrifugation. $J$ Virol Methods 208: 119-124.

Batista MV, Silva MA, Pontes NE, Reis MC, Corteggio A, Castro RS, Borzacchiello G, Balbino VQ, Freitas AC 2013. Molecular epidemiology of bovine papillomatosis and the identification of a putative new virus type in Brazilian cattle. Vet J 197: 368-373.

Bravo IG, Felez-Sanchez M 2015. Papillomaviruses: viral evolution, cancer, and evolutionary medicine. Evol Med Public Health 1: 32-51.

Corteggio A, Altamura G, Roperto F, Borzacchiello G 2013. Bovine papillomavirus E5 and E7 oncoproteins in naturally occurring tumors: are two better than one? Infect Agent Cancer 8: 1.

da Silva FR, Daudt C, Streck AF, Weber MN, Filho RV, Driemeier D, Canal CW 2015. Genetic characterization of Amazonian bovine papillomavirus reveals the existence of four new putative types. Virus genes 51: 77-84.

de Villiers EM, Gunst K 2009. Characterization of seven novel human papillomavirus types isolated from cutaneous tissue but also present in mucosal lesions. J Gen Virol 90: 1999-2004.

Dezen D, Rijsewijk FA, Teixeira TF, Holz CL, Cibulski SP, Franco AC, Dellagostin OA, Roehe PM 2010. Multiply-primed rolling-circle amplification (MPRCA) of PCV2 genomes: applications on detection, sequencing, and virus isolation. Res Vet Sci 88: 436-440.

Garcia-Vallve S, Iglesias-Rozas JR, Alonso A, Bravo IG 2006. Different papillomaviruses have different repertoires of transcription factor binding sites: convergence and divergence in the upstream regulatory region. BMC Evol Biol 6: 20.

Hatama S, Ishihara R, Ueda Y, Kanno T, Uchida I 2011. Detection of a novel bovine papillomavirus type 11 (BPV-11) using xipapillomavirus consensus polymerase chain reaction primers. Arch Virol 156: 1281-1285.

Kumar P, Nagarajan N, Saikumar G, Arya RS, Somvanshi R 2015. Detection of bovine papilloma viruses in wart-like lesions of upper gastrointestinal tract of cattle and buffaloes. Transbound Emerg Dis 62: 264-271.

Lehoux M, D’Abramo CM, Archambault J 2009. Molecular mechanisms of human papillomavirus-induced carcinogenesis. Public Health Genomics 12: 268-280.

Rector A, Lemey P, Tachezy R, Mostmans S, Ghim SJ, Van Doorslaer K, Roelke M, Bush M, Montali RJ, Joslin J, Burk RD, Jenson AB, Sundberg JP, Shapiro B, Van Ranst M 2007. Ancient papillomavirus-host co-speciation in Felidae. Genome Biol 8: R57.

Rijsewijk FA, dos Santos HF, Teixeira TF, Cibulski SP, Varela AP, Dezen D, Franco AC, Roehe PM 2011. Discovery of a genome of a distant relative of chicken anemia virus reveals a new member of the genus Gyrovirus. Arch Virol 156: 1097-1100.

Roperto S, Russo V, Ozkul A, Corteggio A, Sepici-Dincel A, Catoi C, Esposito I, Riccardi MG, Urraro C, Luca R, Ceccarelli DM, Longo M, Roperto F 2013. Productive infection of bovine papillomavirus type 2 in the urothelial cells of naturally occurring urinary bladder tumors in cattle and water buffaloes. PLOS ONE 8: e62227.

Sanjuan R, Nebot MR, Chirico N, Mansky LM, Belshaw R 2010. Viral mutation rates. $J$ Virol 84: 9733-9748.

Titolo S, Pelletier A, Sauve F, Brault K, Wardrop E, White PW, Amin A, Cordingley MG, Archambault J 1999. Role of the ATP-binding domain of the human papillomavirus type $11 \mathrm{E} 1$ helicase in E2dependent binding to the origin. J Virol 73: 5282-5293.

Zheng ZM, Baker CC 2006. Papillomavirus genome structure, expression, and post-transcriptional regulation. Front Biosci 11: 2286-2302. 